\title{
Reduction of Nitroarenes to Anilines with a Benzothiazoline: Application to Enantioselective Synthesis of 2-Arylquinoline Derivatives
}

\author{
Masamichi Miyagawa (D) \\ Ryota Yamamoto \\ Nanako Kobayashi \\ Takahiko Akiyama* (iD \\ Department of Chemistry, Faculty of Science, Gakushuin \\ University, Mejiro, Toshima-ku, Tokyo 171-8588, Japan \\ takahiko.akiyama@gakushuin.co.jp \\ Published as part of the 30 Years SYNLETT - Pearl Anniversary \\ Issue
}

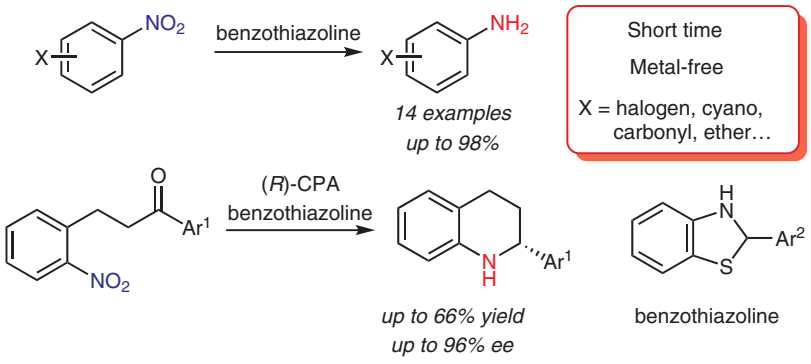

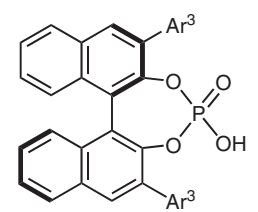

(R)-CPA
Received: 09.10.2018

Accepted after revision: 19.11.2018

Published online: 17.12 .2018

DOI: 10.1055/s-0037-1611639; Art ID: st-2018-b0650-I

License terms: cc)

Abstract The metal-free reduction of nitroarenes to aniline derivatives was accomplished in a short time by using a benzothiazoline as the hydrogen donor in combination with a Brønsted acid. An enantioselective synthesis of 2-arylquinolines was achieved by using 1-aryl-3-(2-nitrophenyl)propan-1-ones as starting materials and a combination of a benzothiazoline and a chiral phosphoric acid.

Key words benzothiazolines, phosphoric acids, isoquinolines, nitroarenes, anilines, reduction

Aniline is a fundamental motif, frequently found in pharmaceuticals, natural compounds, and building blocks. It is also an important building block for organic synthesis. ${ }^{1}$ A conventional method for the synthesis of aniline involves the reduction of aryl nitroarenes by using metals. ${ }^{2}$ The Béchamp reduction, which uses tin or zinc in the presence of a Brønsted acid at high temperature, is extensively employed. ${ }^{3}$ Alternatively, transition-metal-catalyzed reductions of nitroarenes with hydrogen gas are used under relatively mild reaction conditions. Palladium on carbon is a widely used catalyst in reductions performed in the laboratory and industry because it presents benefits with regards to cost and handling. ${ }^{4}$ However, the reduction using palladium is sometimes hampered by such issues as residuals, flammability, and chemoselectivity. The reduction of nitroarenes by using such organic reductants as trichlorosilane $^{5}$ or phenyl(2-pyridyl)methanol ${ }^{6}$ has been developed. Recently, Uozumi and co-workers reported a reduction that used diboronic acid and water. ${ }^{7}$

We have reported an enantioselective transfer hydrogenation of ketimines, in which we used a benzothiazoline (2,3-dihydro-1,3-benzothiazole) as the hydrogen donor in combination with a chiral phosphoric acid. ${ }^{8,9}$ Benzothiazolines proved to be effective for the transfer hydrogenation of $\mathrm{C}=\mathrm{N}$ bonds in a range of ketimines. To expand the utility of benzothiazolines, we set our sights on the reduction of nitroarenes. Here we describe a rapid metal-free reduction of nitroarenes that uses a combination of a benzothiazoline and a Brønsted acid. Furthermore, we applied this reaction to the enantioselective synthesis of 2-arylquinolines, starting from 1-aryl-3-(2-nitrophenyl)propan-1-ones (Scheme 1).

$$
\begin{aligned}
& \text { A) Bechamp reduction (ref. 3) } \\
& \mathrm{Ar}-\mathrm{NO}_{2} \underset{\text { Brønsted acid }}{\stackrel{\text { metal }}{\longrightarrow}} \mathrm{Ar}-\mathrm{NH}_{2}
\end{aligned}
$$

B) Metal-free reduction

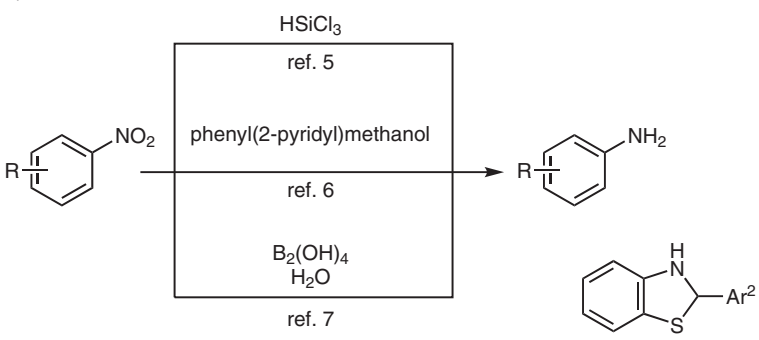

C) This work<smiles></smiles>
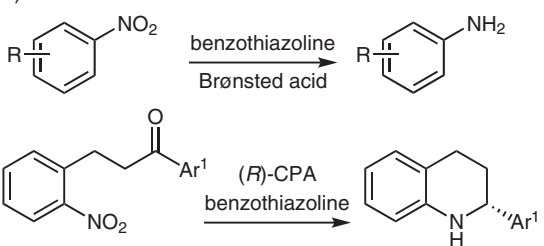

benzothiazoline<smiles></smiles>

(R)-CPA

Scheme 1 Reduction of nitroarenes

At the outset, we examined the reduction of methyl 4nitrobenzoate (1a) with 2-phenylbenzothiazoline (2a) in the presence of a catalytic amount of 10-camphorsulfonic 


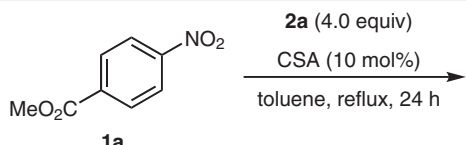

$1 \mathrm{a}$<smiles>CC(=O)c1ccc(NCC(C)C)cc1</smiles>

3a $44 \%$

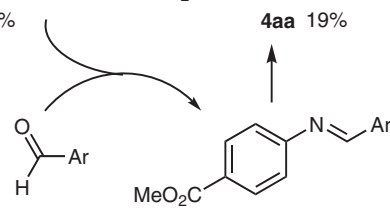

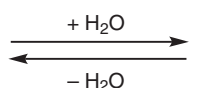<smiles>Nc1ccccc1S</smiles>

$\mathrm{Ar}=4-\mathrm{NCC}_{6} \mathrm{H}_{4}$
5 aa

Scheme 2 Reduction of nitroarenes and the formation of $N$-benzylamine 4aa

acid (CSA) as a Brønsted acid (Scheme 2). Gratifyingly, aniline 3a was obtained in $44 \%$ yield, accompanied by the corresponding $N$-benzylamine 4 aa in $19 \%$ yield. We already knew that the hydrolysis and condensation of benzothiazolines and benzaldehydes occur under these reaction conditions. We therefore believed that 4aa was formed by the reduction of imine 5aa, derived from 3a and 4-cyanobenzaldehyde.

In order to suppress the hydrolysis of the benzothiazoline $\mathbf{2 a}$ and to increase the yield of $\mathbf{3 a}$, we added molecular sieves (MS), which had a pronounced effect; the addition of MS $4 \AA$ suppressed the formation of the benzylamine 4aa and gave aniline 3a in high yield (Table 1, entries 1-3). Next, we explored the effects of the Brønsted acid and of various 2 -substituents on the benzothiazoline. A long reaction time was required in the absence of a Brønsted acid (entry 4). The 2-substituent on the benzothiazoline did not affect the yield (entries 5-7). During the investigations, we had difficulties purifying the aniline after the reaction, because an excess of benzothiazole $\mathbf{6}(\mathrm{Ar}=\mathrm{Ph})$ was generated and the separation of the desired product $\mathbf{3 a}$ from $\mathbf{6}(\mathrm{Ar}=\mathrm{Ph})$ was not a trivial issue. We surmised that the introduction of a carboxy group onto the benzothiazoline $\mathbf{2}$ might increase its polarity and facilitate separation. In addition, we expect-

Table 1 Effects of Molecular Sieves and Various Substituents on the Benzothiazoline

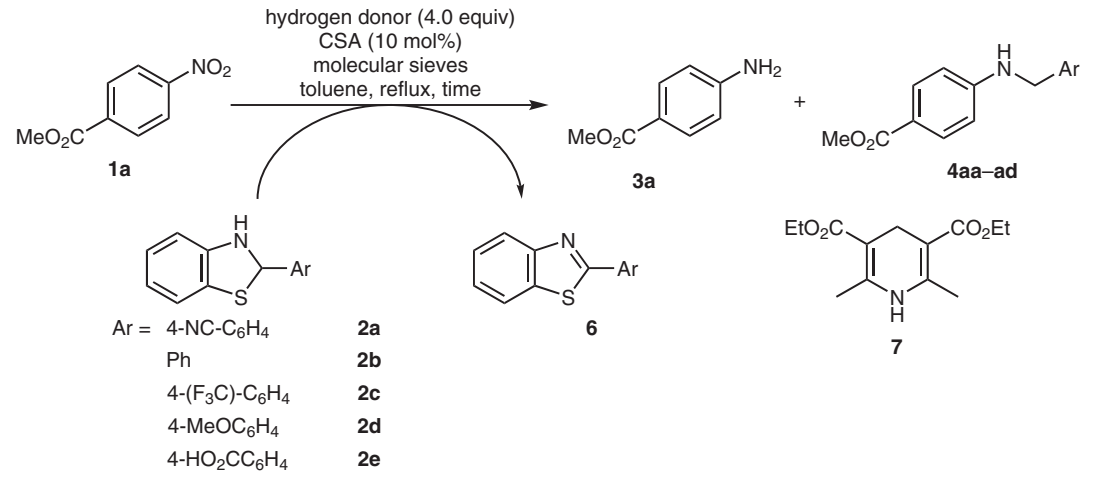

\begin{tabular}{|c|c|c|c|c|c|}
\hline Entry & H donor & MS & Time (h) & Yield (\%) of 3a & Yield (\%) of 4 \\
\hline 1 & $2 a$ & MS $3 \AA ̊$ & 24 & 43 & 0 \\
\hline 2 & $2 a$ & MS 4Å & 24 & 86 & 5 \\
\hline 3 & $2 a$ & MS $5 \AA ̊$ & 24 & 52 & 27 \\
\hline $4^{b}$ & $2 a$ & MS 4Å & 48 & 88 & $<8$ \\
\hline 5 & $2 b$ & MS 4Å & 19 & 84 & 15 \\
\hline 6 & 2c & MS 4尺̊ & 24 & 87 & 10 \\
\hline 7 & $2 d$ & MS 4Å & 10.5 & 75 & $<38$ \\
\hline $8^{\mathrm{b}}$ & $2 e$ & MS 4Å & 0.5 & 98 & - \\
\hline 9 & $2 e$ & MS 4Å & 0.5 & 97 & - \\
\hline 10 & 7 & MS 4Å & 20 & 23 & - \\
\hline
\end{tabular}

a Reaction conditions: $1 \mathrm{a}(0.080 \mathrm{mmol}), \mathrm{H}$ donor $(0.32 \mathrm{mmol}), \mathrm{CSA}(0.008 \mathrm{mmol})$, MS (100 mg), toluene $(0.80 \mathrm{~mL})$.

b Without CSA 
ed that the benzothiazoline bearing a carboxy group $\mathbf{2 e}$ might function as a Brønsted acid instead of CSA. We therefore attempted to perform the reaction with $\mathbf{2 e}$ in the absence of CSA (entries 8 and 9). As expected, benzothiazole 6e was readily removed from the crude mixture by filtration with dichloromethane. Gratifyingly, the use of $\mathbf{2 e}$ accelerated the reaction remarkably and improved the yield of 3a to $98 \%$ in 0.5 hours. We also examined the utility of the Hantzsch ester (7) as a hydrogen donor in place of a benzothiazoline, but this gave 3a in low yield (entry 10). ${ }^{10}$ Benzothiazoline $\mathbf{2 e}$ was therefore found to be the most suitable hydrogen donor for the present reduction.

Having clarified the optimal reaction conditions, we investigated the substrate scope. Nitroarenes bearing electron-withdrawing groups, such as an ester, nitrile, or ketone group, gave the desired anilines $\mathbf{3 b - d}$ in excellent yields (Scheme 3). Bromo- and iodo(nitro)benzenes provided the corresponding anilines $\mathbf{3 e - i}$ in good yields, except for 2bromo-1-nitrobenzene. 4-Methoxy and 4-(benzyloxy)-1nitrobenzenes gave the desired anilines $\mathbf{3 m}$ and $\mathbf{3 n}$ in moderate yields, because benzylamines $4 \mathrm{ma}$ and $4 \mathrm{na}$ were also formed. The reduction was completed in 0.5 hours for all substrates. Aliphatic nitro compounds, nitrobenzenes bearing vinyl groups, and trans- $\beta$-nitrostyrene were not suitable substrates for this reduction, and the corresponding anilines were not obtained.

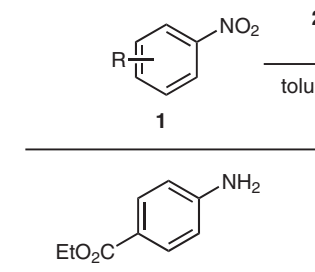

3b $89 \%$<smiles>Nc1ccc(Br)cc1</smiles>

3e $64 \%$

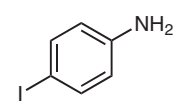

3h $60 \%$

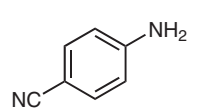

3c $90 \%$<smiles>Nc1cccc(Br)c1</smiles>

3f $60 \%$

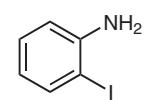

3i $83 \%$
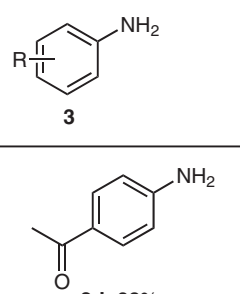

$3 d 83 \%$<smiles>Nc1ccccc1Br</smiles>

3g $27 \%$<smiles>Nc1cccc2ccccc12</smiles>

3k $91 \%$<smiles>Nc1ccc(-c2ccccc2)cc1</smiles>

3j $74 \%$

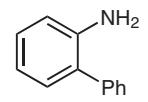

3I $74 \%$

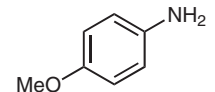

$3 m \quad 46 \%$

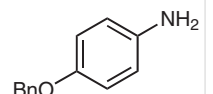

3n $55 \%$
Scheme 3 Substrate scope of nitroarenes

We hypothesized that the reduction proceeds by a radical pathway. 2,2,6,6-Tetramethylpiperidine 1-oxyl (TEMPO) and 2,6-di-tert-butyl-4-methylphenol (BHT) were added to the reaction mixture as radical scavengers. The addition of TEMPO suppressed the reduction completely, and $96 \%$ of 1a was recovered. On the other hand, amine 3a was obtained in $85 \%$ yield when BHT was added (Scheme 4 ). The latter result did not agree with our hypothesis, so we are exploring other reaction pathways.

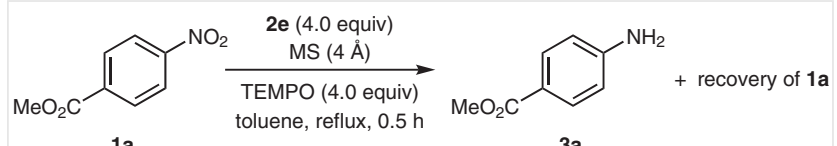

$1 \mathrm{a}$

$0 \%$
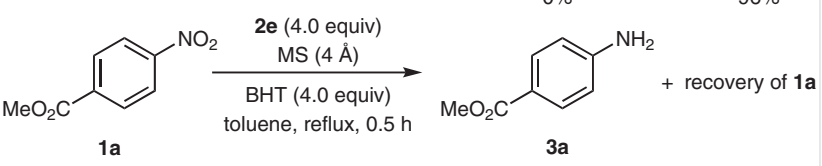

$0 \%$

Scheme 4 Mechanistic study

The present reduction of nitroarenes was applied in a tandem reaction to synthesize 2 -substituted chiral quinoline derivatives (Scheme 5). ${ }^{11}$ The tandem reaction consists of (I) reduction of a 1-aryl-3-(2-nitrophenyl)propan-1-one 9, (II) imine formation by intramolecular cyclization, and (III) asymmetric reduction by a chiral phosphoric acid and a benzothiazoline. ${ }^{12}$

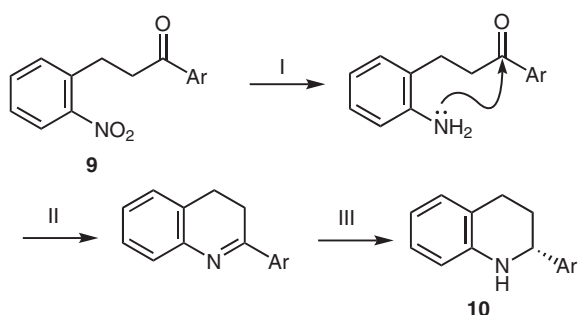

Scheme 5 Tandem reaction

We optimized the reaction conditions to furnish the desired 2-arylquinolines 10a-c in good yields and with excellent enantioselectivities by the combined use of benzothiazoline $\mathbf{2 f}$ and chiral phosphoric acid $\mathbf{8}$ (Scheme 6). ${ }^{13}$

In summary, we have developed a reduction of nitroarenes by using a benzothiazoline in the presence of a Brønsted acid. The reduction with a benzothiazoline bearing a carboxy group was completed in a short time. Selective reduction without use of metal reagents was achieved. A tandem reaction with a chiral phosphoric acid and a benzothiazoline gave 2-aryltetrahydroquinoline derivatives with excellent enantioselectivities.

\section{Funding Information}

This work was partially supported by a Grant-in-Aid for Scientific Research on Innovative Areas "Advanced Transformation Organocatalysis" from MEXT, Japan, and JSPS KAKENHI Grant Number JP17H03060. 
<smiles>O=C(I)CCc1ccccc1[N+](=O)[O-]</smiles>

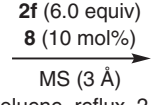
toluene, reflux, 2<smiles>c1ccc([C@@H]2CCc3ccccc3N2)cc1</smiles>
$10 \mathrm{a}$ $60 \%, 92 \%$ ee<smiles>c1ccc2c(c1)CC[C@H](c1ccc3ccccc3c1)N2</smiles>

$10 \mathrm{c}$

$66 \%, 84 \%$ ee<smiles>[Bi]C1CCc2ccccc2N1</smiles>

10<smiles>Clc1ccc([C@@H]2CCc3ccccc3N2)cc1</smiles>

$10 \mathrm{~b}$ $60 \%, 96 \%$ ee

Scheme 6 Asymmetric synthesis of 2-substituted quinolines

\section{Supporting Information}

Supporting information for this article is available online at https://doi.org/10.1055/s-0037-1611639.

\section{References and Notes}

(1) (a) Downing, R. S.; Kunkeler, P. J.; van Bekkum, H. Catal. Today 1997, 37, 121. (b) Lawrence, S. A. Amines: Synthesis, Properties and Applications; Cambridge University Press: Cambridge, 2004. (c) MacDiarmid, A. G. Synth. Met. 1997, 84, 27.

(2) For reviews, see: (a) Kadam, H. K.; Tilve, S. G. RSC Adv. 2015, 5, 83391. (b) Blaser, H.-U.; Steiner, H.; Studer, M. ChemCatChem 2009, 1, 210. (c) Orlandi, M.; Brenna, D.; Harms, R.; Jost, S.; Benaglia, M. Org. Process Res. Dev. 2018, 22, 430. (d) Aditya, T.; Pal, A.; Pal, T. Chem. Commun. 2015, 51, 9410.

(3) Béchamp, A. Ann. Chim. Phys. 1854, 42[3], 186.

(4) Blaser, H.-U. Chimia 2015, 69, 393.

(5) (a) Porta, R.; Puglisi, A.; Colombo, G.; Rossi, S.; Benaglia, M. Beilstein J. Org. Chem. 2016, 12, 2614. (b) Orlandi, M.; Tosi, F.; Bonsignore, M.; Benaglia, M. Org. Lett. 2015, 17, 3941. (c) Orlandi, M.; Benaglia, M.; Tosi, F.; Annunziata, R.; Cozzi, F. J. Org. Chem. 2016, 81, 3037.

(6) Giomi, D.; Alfini, R.; Brandi, A. Tetrahedron 2011, 67, 167.

(7) Chen, D.; Zhou, Y.; Zhou, H.; Liu, S.; Liu, Q.; Zhang, K.; Uozumi, Y. Synlett 2018, 29, 1765.

(8) (a) Zhu, C.; Akiyama, T. Org. Lett. 2009, 11, 4180. (b) Zhu, C.; Saito, K.; Yamanaka, M.; Akiyama, T. Acc. Chem. Res. 2015, 48, 388. (c) Zhu, C.; Akiyama, T. Synlett 2011, 1251.

(9) For seminal papers on chiral phosphoric acid catalysis, see: (a) Akiyama, T.; Itoh, J.; Yokota, K.; Fuchibe, K. Angew. Chem. Int. Ed. 2004, 43, 1566. (b) Uraguchi, D.; Terada, M. J. Am. Chem. Soc. 2004, 126, 5356. For selected reviews, see: (c) Akiyama, T. Chem. Rev. 2007, 107, 5744. (d) Terada, M. Synthesis 2010, 1929. (e) Parmar, D.; Sugiono, E.; Raja, S.; Rueping, M. Chem. Rev.
2014, 114, 9047. (f) Parmar, D.; Sugiono, E.; Raja, S.; Rueping, M. Chem. Rev. 2017, 117, 10608. (g) Merad, J.; Lalli, G.; Bernadat, G.; Maur, J.; Masson, G. Chem. Eur. J. 2018, 24, 3925.

(10) For pioneering works on chiral phosphoric acid-catalyzed transfer hydrogenation of ketimines by using the Hantzsch ester as a hydrogen donor, see: (a) Rueping, M.; Sugiono, E.; Azap, C.; Theissmann, T.; Bolte, M. Org. Lett. 2005, 7, 3781. (b) Hoffmann, S.; Seayad, A.; List, B. Angew. Chem. Int. Ed. 2005, 44, 7424. (c) Storer, R. I.; Carrera, D. E.; Ni, Y.; MacMillan, D. W. C. J. Am. Chem. Soc. 2006, 128, 84; For selected reviews, see. (d) Rueping, M.; Sugiono, E.; Schoepke, F. R. Synlett 2010, 852. (e) Zheng, C.; You, S.-L. Chem. Soc. Rev. 2012, 41, 2498.

(11) For an enantioselective metal-free cascade reaction with a chiral phosphoric acid, see: Rueping, M.; Antonchick, A. P.; Theissmann, T. Angew. Chem. Int. Ed. 2006, 45, 3683.

(12) Shibata, Y.; Yamanaka, M. J. Org. Chem. 2013, For a theoretical study on chiral phosphoric acid-catalyzed transfer hydrogenation using a benzothiazoline, see: 78, 3731 .

(13) 2-Aryl-1,2,3,4-tetrahydroquinolines 10a-c; General Procedure

Under a $\mathrm{N}_{2}$ atmosphere, a mixture of the appropriate ketone $\mathbf{9}$ ( $0.10 \mathrm{mmol})$, benzothiazoline $\mathbf{2 f}(0.60 \mathrm{mmol})$, chiral phosphoric acid $8(0.010 \mathrm{mmol})$, and MS $3 \AA$ ( $600 \mathrm{wt} \%$, activated) in toluene $(1.0 \mathrm{~mL})$ was refluxed for 2 days. When the reaction was complete (TLC), it was quenched by adding sat. aq $\mathrm{NaHCO}_{3}$. The crude mixture was filtered through a Celite pad and extracted with EtOAc $(\times 3)$. The organic extracts were combined, washed with brine, dried $\left(\mathrm{Na}_{2} \mathrm{SO}_{4}\right)$, and concentrated in vacuo. The residue was purified by preparative TLC.

2-Phenyl-1,2,3,4-tetrahydroquinoline (10a)

White solid; yield: $13 \mathrm{mg}\left(60 \%, 92 \%\right.$ ee); $\mathrm{mp} 52-54{ }^{\circ} \mathrm{C} ;[\alpha]_{\mathrm{D}}{ }^{24}-42$ (c $0.75, \mathrm{CHCl}_{3}$ ). ${ }^{1} \mathrm{H}$ NMR $\left(400 \mathrm{MHz}, \mathrm{CDCl}_{3}\right): \delta=1.94-2.05(\mathrm{~m}, 1$ $\mathrm{H}), 2.09-2.15(\mathrm{~m}, 1 \mathrm{H}), 2.74(\mathrm{dt}, J=4.8,16.4 \mathrm{~Hz}, 1 \mathrm{H}), 2.93$ (ddd, $J=5.6,10.8,16.4 \mathrm{~Hz}, 1 \mathrm{H}$ ), 4.04 (br s, $1 \mathrm{H}), 4.43$ (dd, $J=3.4,9.2$ $\mathrm{Hz}, 1 \mathrm{H}), 6.53$ (d, J = 8.4 Hz, $1 \mathrm{H}), 6.65$ (t, $J=7.6 \mathrm{~Hz}, 1 \mathrm{H}), 6.99-$ $7.02(\mathrm{~m}, 2 \mathrm{H}), 7.24-7.40(\mathrm{~m}, 5 \mathrm{H}) .{ }^{13} \mathrm{C}$ NMR $\left(100 \mathrm{MHz}, \mathrm{CDCl}_{3}\right)$ : $\delta=26.4,31.0,56.3,114.0,117.2,120.9,126.6,126.9,127.5$, 128.6, 129.3, 144.7, 144.8 . 